\title{
CORRECTIONS
}

\section{Screening tests: indices of performance}

Mistyping led to a mistake in the final option (d) of this Endgames statistical question by Philip Sedgwick (BMJ 2011;342:d3763, doi:10.1136/bmj.d3763). It currently reads
$(294 /(34+2)) \times 100 \%=99.3 \%$, but it should read $(294 /(294+2)) \times 100 \%=99.3 \%$.

Cite this as: $B M J 2011 ; 342: \mathrm{d} 4153$ 